\title{
Introduction:
}

There are two parts to this lab: the first part involves creating an acetanilide from aniline using an acetylation reaction, and the second part involves reacting an unknown substituted aniline, and characterizing the product to identify the starting aniline. The methods used to characterize the products formed in both the first, and second parts of the experiment are thin layer chromatography (TLC), infrared (IR) spectroscopy, and melting point. TLC co-spots are used as evidence that the reaction took place, and to assess purity of the final products. IR spectroscopy is employed in order to obtain information on the functional groups present on the beginning, and recrystalized products. Melting point is used in order to gain further information about what the particular unknown compound is. In the second part of the experiment, the Beilstein Test will also be employed to detect the presence of a halogen in the unknown compound.

This experiment deals with carbonyl chemistry, solubility, and, as mentioned above, characterizing compounds. Solubility in water is a big issue in this experiment, as the aniline, and the substituted unknown aniline are water insoluble, and have to be protonated to dissolve in water, and then deprotonated to undergo a reaction with acetic anhydride. Recrystallization took place after the reaction was fully completed in order to characterize the final products using the techniques mentioned above.

\section{Reaction Scheme:}

Part 1
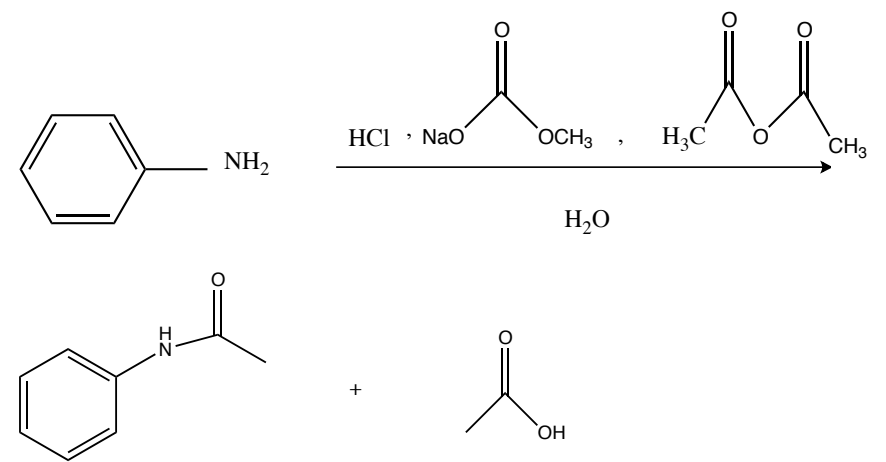

Part 2 


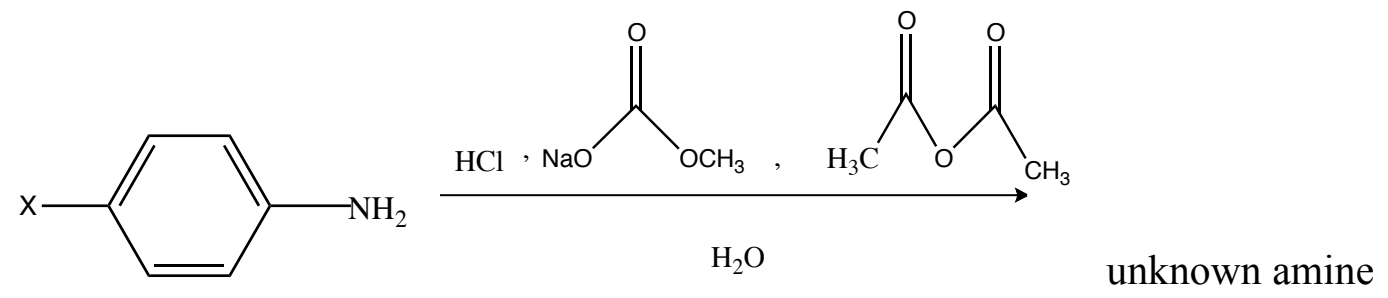

( $\mathrm{x}=$ an unknown substituent group)

\section{Experimental:}

Aniline (529.4 mg, $5.68635 \mathrm{mmol})$ was added to $14 \mathrm{~mL}$ of water in a $50 \mathrm{~mL}$ round-bottom flask (in part two, the aniline is replaced by $513.9 \mathrm{mg}$ of unknown substituted aniline). Concentrated (37\%) hydrochloric acid (.45 mL, $14.62 \mathrm{mmol})$ was then added to the flask, and the mixture was stirred to dissolve the aniline, followed by the addition of acetic anhydride $(.6 \mathrm{~mL}, 6.388 \mathrm{mmol})$ to the flask. In a separate $25 \mathrm{~mL}$ round-bottom flask sodium acetate $(545.8 \mathrm{mg}, 6.65366 \mathrm{mmol}$ for part 1 and $541 \mathrm{mg}$, $6.59514 \mathrm{mmol}$ for part 2) was added to $3 \mathrm{~mL}$ of water. The mixture of sodium acetate was then poured into the homogenous aniline mixture, the contents were stirred, and placed in an ice bath while the reaction occurred: forming a precipitate. The precipitate was then filtered using vacuum filtration, weighed, and then placed in a clean flask. Ethanol (95\%) was heated using a hot plate, and the minimal amount of ethanol was used to completely dissolve the solid precipitate while it was placed on the hot plate $(1.4 \mathrm{ml}$, and $3.5 \mathrm{ml}$ for part 2). The flask cooled in an ice bath while recrystallization took place, and vacuum filtration was employed in order to obtain the crystals. For Part 1 IR data was obtained on the acetanilide. Additionally, TLC data was obtained using a 1:1 ethyl acetate: hexane- developing solution. For Part 2 the Beilstein test for halogens was employed on the beginning unknown. Melting point, and IR data were obtained on the beginning unknown substituted amine, and the unknown acetamide. TLC data was obtained using a 1:1 ethyl acetate: hexane- developing solution.

\section{Results and Discussion:}

In part one, after the initial funnel step, $410 \mathrm{mg}$ of the white precipitate was massed out, but after crystallization only $60 \mathrm{mg}$ of the product was recovered. The percent yield of the reaction was determined to be $100(60 \mathrm{mg}$ )/ 725.796 (theoretical yield) $\mathrm{mg}=8.219 \%$. The melting point of the acetanilide was determined to be in the range of $110-112^{\circ} \mathrm{C}$ (see page 10 of lab pages). 
The major tool used to characterize the product in the first part of the experiment was TLC. As seen on page 09 of the attached lab pages, a co-spot was employed using pure aniline as one standard, and the crystals formed in the last step of the experiment as the second standard. The developing solution was a ratio of 1:1 of ethyl acetate: hexane. The $R_{\mathrm{f}}$ values were calculated at the top of the spots on the TLC plate, and were as follows: .49054 for aniline, and .27027 for the crystal product. This means the product is different from the starting material, and the co-spot matches the two standards, and again shows the differences in the starting, and end materials. The crystal product is more polar than the beginning aniline, which we would have predicted if the reaction was fully carried out due to the addition of the acetyl group. The TLC results also show that the final product is pure, due to the presence of only one $\mathrm{R}_{\mathrm{f}}$ for the compound.

The IR data collected on the aniline, and recovered crystals shows the major difference between the aniline, and the recovered crystals is a replacement of one of the hydrogen atoms on the nitrogen atom with a carbonyl group. The IR spectra of the final product show the presence of a carbonyl group, an $\mathrm{N}-\mathrm{H}$ stretch, and the presence of an aromatic ring (see page 16 of lab pages). In comparison, the aniline has $\mathrm{N}-\mathrm{H}$ stretching as well as an aromatic ring in the functional group region of the IR spectra, but not the carbonyl group (see page 15 of lab pages). The presence of a carbonyl group in the IR spectra of our final product is evidence that the desired acetylation reaction with aniline occurred.

In part two of the experiment, $57 \mathrm{mg}$ of the brown precipitate was recovered in recrystallization. The percent yield of the second part is approximately $100(57 \mathrm{mg}) / 730$ $\mathrm{mg}=7.808 \%$. Since an unknown substituted aniline was used, the actual percent yield will be lower since both the starting, and ending aniline derivatives would have higher molecular weights, and thus the theoretical yield value would be larger. A Beilstein test confirmed there was no halogen present in the beginning compound of part two. The starting material was liquid at room temperature, and therefore no melting point assessment was required. The melting point of the product formed in the reaction was between $74-77^{\circ} \mathrm{C}$ (see page 13 of lab pages), which close to the $81{ }^{\circ} \mathrm{C}$ listed for the acetamide of meta-anisidine. 


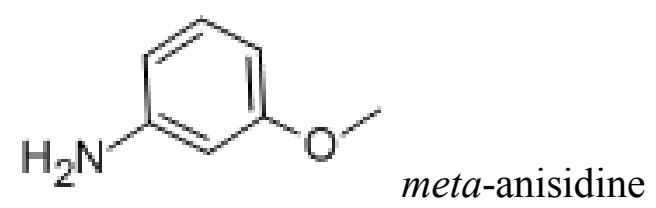

TLC was used to assess the differences between the starting unknown material, and the final recrystalized unknown. A co-spot was employed using the pure unknown as one standard, and the crystals formed in the last step of the experiment as the second standard. The developing solution was a ratio of 1:1 of ethyl acetate: hexane. The $\mathrm{R}_{\mathrm{f}}$ values were calculated at the top of the spots on the TLC plate, and were as follows: .46515 for the pure unknown, and .02325 for the crystal product. (see page 13 of lab pages). The difference between the calculated $R_{f}$ for the compounds shows the final crystal product differed from the beginning pure unknown. The final crystal product is more polar. The TLC results also show that the final product is pure, due to the presence of only one $\mathrm{R}_{\mathrm{f}}$ for the compound.

The IR data collected on the beginning pure starting material, and the unknown acetamide showed a hydrogen on the nitrogen was replaced with a carbonyl group. The IR spectra of the final product show the presence of a carbonyl group, an $\mathrm{N}-\mathrm{H}$ stretch, the presence of an aromatic ring, and the presence of a $\mathrm{C}-\mathrm{O}$ bond (see page 19 of lab pages). In comparison, the pure unknown has an $\mathrm{N}-\mathrm{H}$ stretching, an aromatic ring, and a $\mathrm{C}-\mathrm{O}$ bond in the functional group region of the IR spectra, but not the carbonyl group (see page 17 of lab pages). The presence of a carbonyl group in the IR spectra of our final product is evidence that the desired acetylation reaction occurred. The IR spectra also served as strong evidence that the unknown compound is in fact meta-anisidine due to the presence of an $\mathrm{N}-\mathrm{H}$ stretch, the presence of an aromatic ring, and the presence of a $\mathrm{C}-$ $\mathrm{O}$ bond, which is what would be expected in an IR of meta-anisidine.

\section{Conclusion:}

Part one of the experiment did produce the desired product. The TLC co-spot confirmed that a different, more polar compound was produced, and the IR spectra of the product showed a carbonyl group was added, as well as the expected $\mathrm{N}-\mathrm{H}$ stretches and aromatic $\mathrm{C}-\mathrm{H}$ bonds still being present. In part two there was a larger body of evidence to support the claim that the desired product formed. The TLC data showed a more polar, different compound formed, the IR data showed a carbonyl group was added, as well as 
the expected $\mathrm{N}-\mathrm{H}$ stretches, aromatic $\mathrm{C}-\mathrm{H}$, and $\mathrm{C}-\mathrm{O}$ groups still present. The melting point test revealed that our final product had a melting point that was consistent, along with the IR data indicating a $\mathrm{C}-\mathrm{O}$ group, to that of meta-anisidine. Both of our products were considered to be pure based on the TLC data. Only one $\mathrm{R}_{\mathrm{f}}$ appeared on the TLC plate per each product, therefore there was only one compound present in the sample, and therefore we can consider our products to be pure.

In order to improve this experiment there needs to be a better way to ensure that precipitate was not lost between each step in the vacuum filtration, and recrystallization steps. The precipitate clung to the sides of the glassware, and was lost with each step therefore making it impossible to recover. Washing with water, and then boiling off the water could allow for the extra precipitate to be added back to the reaction, and thus would give higher yields to the products.

\section{References:}

ChemBook. M-Anisidine.

http://www.chemicalbook.com/ChemicalProductProperty_EN_CB4203315.htm (May 14, 2012).

Glagovich, Neil. Infrared Spectroscopy Outline.

http://www.chemistry.ccsu.edu/glagovich/teaching/316/ir/ir.html (May 10,2012).

Schultz, Ginger. Experiment 1. https://ctools.umich.edu/portal/site/2f418e75-55c2-4c8d-

$\underline{8 d 4 c-108 \text { eabcbcf73 }}$ (May 13,2012). 